\title{
ИССЛЕДОВАНИЕ ЭКОНОМИЧЕСКОГО СОТРУДНИЧЕСТВА МЕЖДУ ПРОВИНЦИЕЙ ХЭЙЛУНЦЗЯН КИТАЯ И ДАЛЬНИМ ВОСТОКОМ РОССИИ 1
}

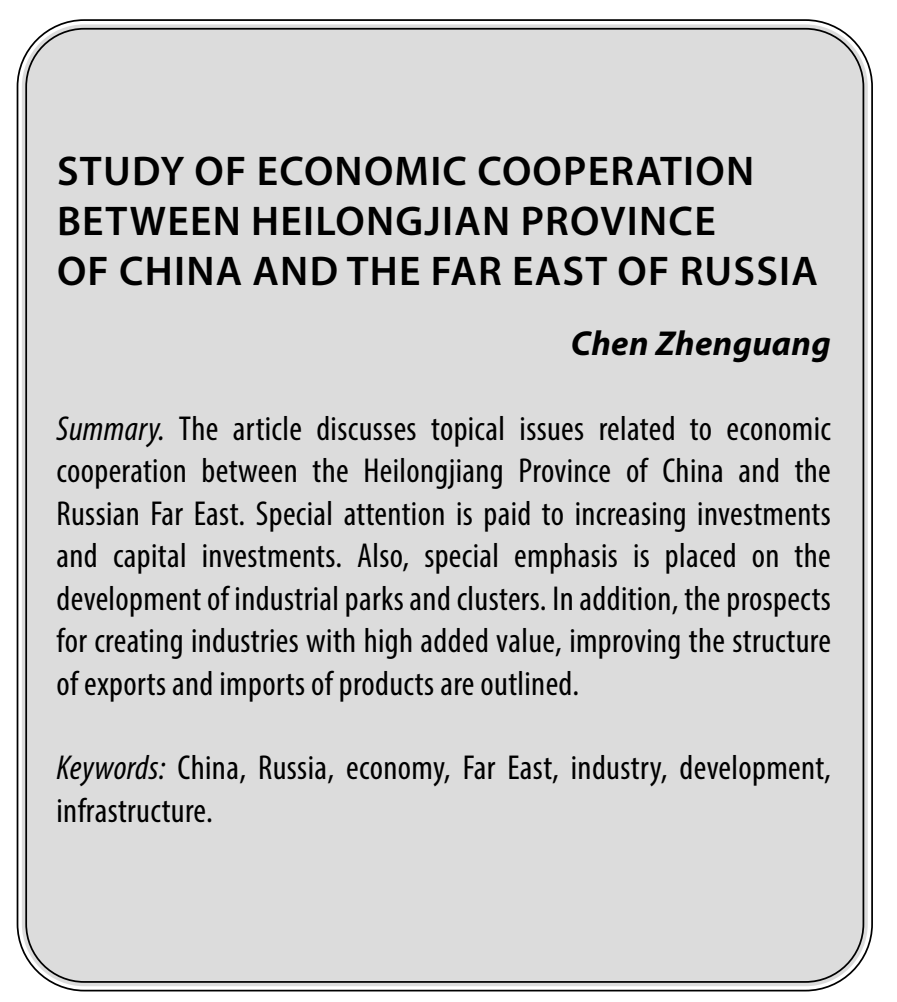

B последние годы наблюдаются ощутимые изменения в стратегии внешней политики Китайской Народной Республики, интересы которой выходят далеко за пределы Азиатско-Тихоокеанского региона. Например, глобальная инициатива КНР «Один пояс, один путь» охватывает более 70 стран, особое вместо в которой принадлежит России. Китай и Россия имеют тесные торгово-экономические отношения. В 2019 году общий объем двусторонней торговли между Китаем и Россией составил 110,794 млрд. долларов США, увеличившись на 3,4\% по сравнению с аналогичным периодом прошлого года, в том числе экспорт Китая составил 49,74 млрд. долларов США, а импорт из России - 55,39 млрд. долларов США [1].

Особо активно российско-китайские экономические отношения развиваются на Дальнем Восто-

\author{
Чэнь Чжэньгуан \\ Старший преподаватель, Хэйхэский университет \\ 1060396560@qq.com
}

Аннотация. В статье рассмотрены актуальные вопросы, связанные с экономическим сотрудничеством между провинцией Хэйлунцзян Китая и Дальним Востоком России. Отдельное внимание уделено наращиванию инвестиций и капиталовложений. Также особый акцент сделан на развитии промышленных парков и кластеров. Кроме того, обозначены перспективы создания производств с высокой добавленной стоимостью, улучшении структуры экспорта и импорта продукции.

Ключевые слова: Китай, Россия, экономика, Дальний Восток, промышленность, развитие, инфраструктура.

ке России, поскольку данная территория примыкает к Северо-Восточному Китаю, вследствие чего многие китайские инвесторы вкладывают средства в объекты и инфраструктуру этого региона. В свою очередь в 2020 году правительство России утвердило Государственный план развития Дальнего Востока. План будет реализован в три этапа с конечным сроком завершения в 2035 году, его целью является ускорение экономического и социального роста, а также повышение уровня жизни жителей региона. Значительное внимание в данном плане уделено сотрудничеству между провинцией Хэйлунцзян Китая и Дальним Востоком России. Российско-китайское сотрудничество «Дальний Восток-Северо-Восток» осуществляется в сферах дорожно-мостового строительства, энергетики, арктических водных путей, промышленности, сельского и лесного хозяйства.

1 Данная статья публикуется в рамках научно-исследовательского проекта основного операционного расхода вузов провинции Хэйлунцзян 2019 г. на тему «Исследование нового пути экономического и торгового сотрудничества между провинцей Хэйлунцзян и Россией на фоне создания китайского-российского моста Хэйлунцзян» Проект 2019-KYYWF-0457 


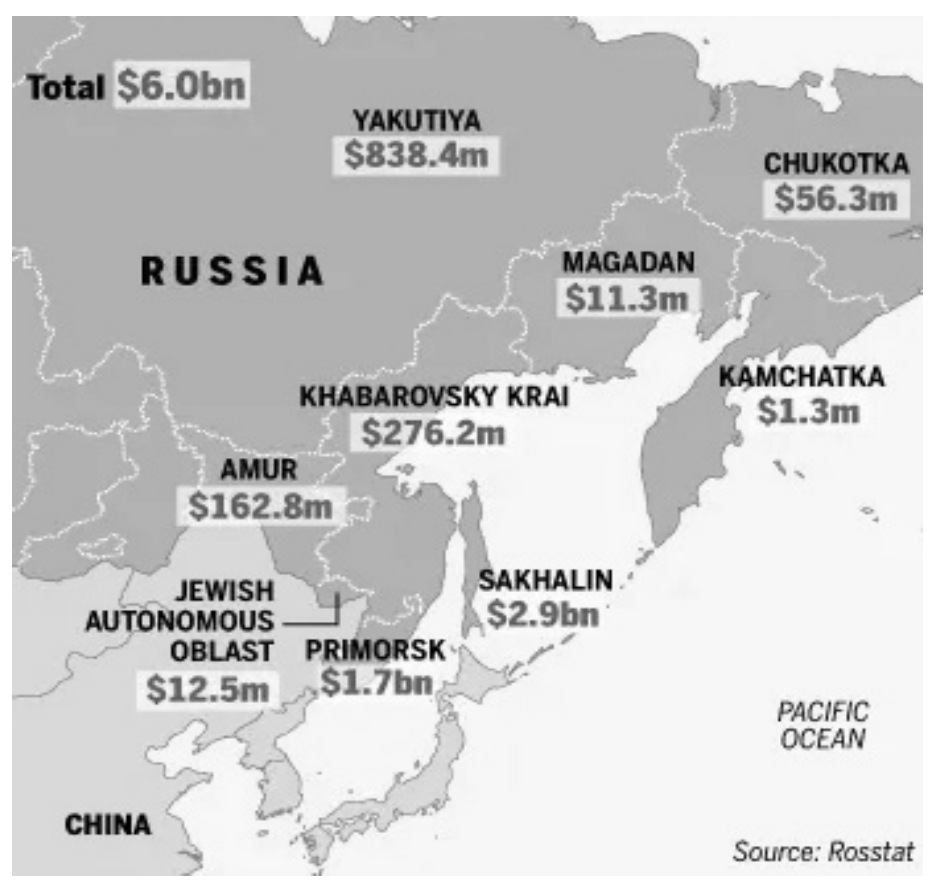

Рис. 1. Инвестиции китайских компаний в объекты на Дальнем Востоке России [4]

Отдельный акцент необходимо сделать на том, что ключевые акценты Государственного плана развития Дальнего Востока включают в себя:

- исследование рынков стран и регионов вдоль «Нового Шелкового пути»;

- укрепление сотрудничества в области научных и технологических инноваций;

- активное расширение торгово-экономического сотрудничества;

- углубление двустороннего инвестиционного взаимодействия.

Инвестиции провинции Хэйлунцзян в Россию составляют более трети всех вложений Китая в Россию и в основном они сосредоточены на Дальнем Востоке. Согласно статистике, в 2006 году 31 компания провинции Хэйлунцзян инвестировала в Россию. К 2008 году количество компаний увеличилось до 65. В 2011 году количество субъектов хозяйствования, вкладывающих капитал в РФ, одобренных провинцией Хэйлунцзян и поданных в Министерство торговли России, достигло 374 с совокупным объемом инвестиций 2,45 миллиарда долларов США. В 2020 году численность инвесторов в Дальний Восток России из Хэйлунцзяна достигли отметки 543. На долю Китая в настоящее время приходится 59,1\% иностранных инвестиций в зоне опережающего развития Дальнего Востока России [2].

С учетом вышеизложенного, бесспорно, налаживание тесных контактов между Северо-Восточным Китаем и Дальним Востоком России (Китай-Россия «Северо-Вос-
ток-Дальний Восток») открывает новые возможности для развития двух стран, придавая импульс углублению всеобъемлющего стратегического партнерства и сотрудничества между Китаем и Россией в новую эпоху, поэтому исследование перспектив развития взаимовыгодных экономических отношений в данном направлении представляет собой важную научно-практическую задачу, решению которой и посвящена данная статья.

Факторы развития российско-китайского экономического сотрудничества детально рассматриваются в работах Engin Selçuk; Wu, Fengshi; Martus, Ellie; Liu, Dawei; Xu, Hang; Смирнова А.И., Мирошиной Е.А., Васильевой Н.И., Рау И., Симонян Г.А.

Ключевые направления активизации сотрудничества между Украиной и Китаем на основе обобщения достижений в реализации инициативы «Один пояс один путь» детально прорабатываются Tilman Pradt, Gao, Tianming; Erokhin, Vasilii; Wang, Chengfu; Huang, Chengfeng; Guan, Haichang; Zeng, Tao; Wang, Tingsong.

Непосредственно особенности торгово-экономических связей провинции Хэйлунцзян с российским Дальним Востоком анализируются Лу Ч., Дацышеном В.Г., Кузенко В.В., Джэном С., Цзоу С. и др.

Однако, несмотря на имеющиеся достижения и наработки, вопросы развития и реализации внешнеэкономического потенциала сотрудничества провинции Хэйлунцзян Китая и Дальнего Востока России требует 
от экономической науки более тщательного изучения и исследования.

Таким образом, цель статьи заключается в исследовании ключевых направлений и перспектив экономического сотрудничества между провинцией Хэйлунцзян Китая и Дальним Востоком России.

Активизация взаимодействия между Китаем и Россией привело к быстрому развитию экономики на Дальнем Востоке России, при этом обе стороны наблюдают рост объемов торговли и трансграничных энергетических и инфраструктурных проектов.

Так, начиная с 2009 года было подано заявки на 208 основных проекта, 97 из них находятся в России и предполагают инвестиции в размере 44,03 млрд. дол. В свою очередь в Китае расположены 111 проектов с общим объемом вложений приблизительно 9,87 млрд. дол. Из числа этих проектов около 70 предусматривают строительство трансграничной инфраструктуры, 20 - это крупные международные проекты с участием Китая и России, в том числе проект моста Тунцзян через реку Амур. Другие 19 проектов находятся на российской стороне и требуют общих инвестиций порядка 40 млрд. дол., остальные 31 располагаются на китайской стороне - преимущественно в провинции Хэйлунцзян и районе Внутренняя Монголия [3].

На рис. 1 представлен объем средств, вкладываемых китайскими инвесторами в предприятия и объекты на Дальнем Востоке России.

Рассматривая более подробно направления экономического сотрудничества между провинцией Хэйлунцзян Китая и Дальним Востоком России, можно отметить следующие ключевых векторы.

Во-первых, это строительство международного центра научно-технических инноваций, а также кластера передовой обрабатывающей промышленности мирового класса, что позволит еще больше расширить открытость и создаст новые преимущества для международного торгового сотрудничества.

Во-вторых, участие китайских инвесторов в создании 49 зон опережающего развития и проектах свободного порта Владивосток. Общий объем инвестиций составляет 2,7 миллиарда долларов США. В стадии подготовки находится 40 инвестиционных проектов на сумму более 23 миллиардов долларов США.

По имеющимся данным, на Дальнем Востоке России крупнейшими проектами с участием китайского капитала являются проект по добыче золота с участием China National Gold Group, угольный проект с участием
China Energy, Находкинский завод минеральных удобрений с участием China Chengda Engineering Co., Ltd. и China Ding United Animal Husbandry.

Особый акцент необходимо сделать на углублении сотрудничества между горнодобывающими компаниями из Китая и России и создании промышленного кластера стоимостью триллион юаней. После того, как будут построены приграничные железные дороги и автомагистрали, сотрудничество в сфере оптовых поставок станет реальностью, что будет способствовать развитию новых промышленных кластеров. Согласно информации властей провинции Хэйлунцзян, разработка, использование и интенсивная переработка полезных ископаемых должны достичь 230 миллиардов юаней, плюс переработка нефти и природного газа. В частности, обозначенные инициативы позволят укрепить сотрудничество между Harbin Electric Group в Хэйлунцзян, Северо-восточным заводом легких сплавов, Hafei Company, Harbin Bearing Factory, Jiamusi Electric Co., Ltd. и крупными центральными предприятиями, такими как China Minmetals Corporation.

В-третьих, реализация трех проектов по переработке российской продукции в районе Суйфэньхэ в зоне свободной торговли Хэйлунцзян в Китае: импорт российской высококачественной муки, меда и других сельскохозяйственных продуктов для развития пищевой промышленности, импорт омела, пастернака, астрагала и других китайских лекарственных материалов.

В-четвертых, инновационные модели сотрудничества в области энергетики и ресурсов. В стратегические планы России не входит в долгосрочной перспективе продолжать поставки сырья в Китай, а экспорт из Северо-Восточного Китая на Дальний Восток в свою очередь не может долго базироваться на низкопробных товарах легкой промышленности и товарах повседневного спроса. Таким образом, обе стороны нацелены на углубленное сотрудничество в оптимизации структуры импорта и экспорта продукции, а также изучение возможностей расширения потенциала энергетической отрасли в двух регионах. Другими словами, целью экономического взаимодействия является осуществление прорыва в области энергетики, развитие экспортных направлений, ориентированных на энергетику.

Таким образом, подводя итоги отметим, что налаживание эффективных экономических связей между провинцией Хэйлунцзян Китая и Дальним Востоком России может решить проблемы России в области капитала, технологий, строительства и эксплуатации предприятий. А минеральные ресурсы Дальнего Востока в свою очередь будут способствовать поддержке и стимулированию экономического роста провинции Хэйлунцзян. 


\section{ЛИТЕРАТУРА}

1. Wang, Peijie Science, technology and innovation policy in Russia and China - Mapping and comparisons in objectives, instruments and implementation // Technological forecasting and social change. Volume 162; pp 13-19.

2. Russia in a Changing World / Glenn Diesen, Alexander Lukin. Singapore: Palgrave Macmillan, 2020. 196 p.

3. Power of Siberia: a natural gas pipeline brings Russia and China closer / Michael Ratner, Heather L. Greenley. Washington: Congressional Research Service, 2020. $141 \mathrm{p}$.

4. The Belt and Road Initiative, Asian infrastructure investment bank, and the role of enterprise heterogeneity in China's outward foreign direct investment // Post-communist economies. 2021; Number 4; pp 379-401.

(c) Чэнь Чжэньгуан ( 1060396560@qq.com )

Журнал «Современная наука: актуальные проблемы теории и практики»

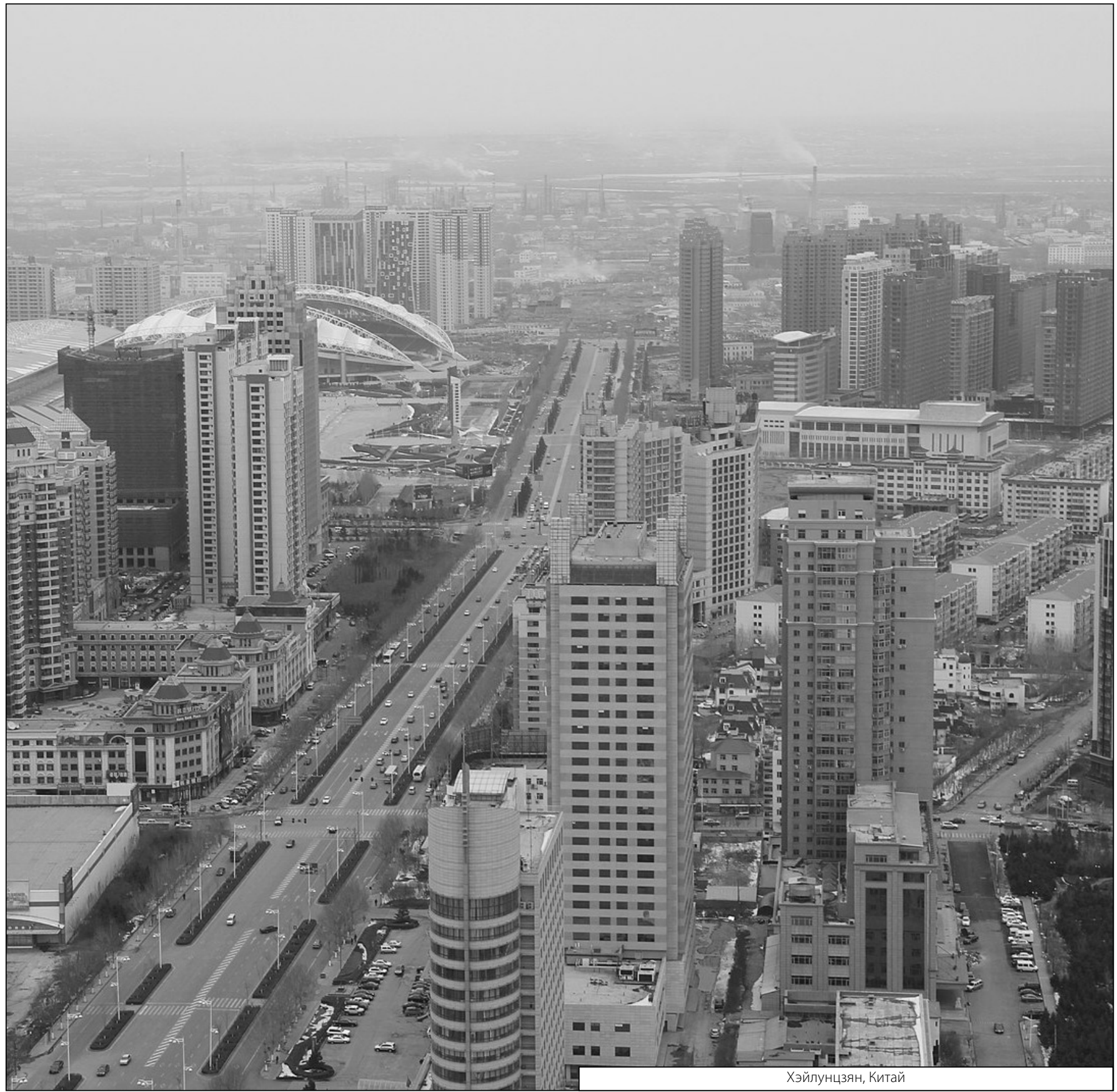

